\title{
Ceramic Based Intelligent Piezoelectric Energy Harvesting Device
}

\author{
Imran Patel ${ }^{1,2}$ \\ ${ }^{1}$ British University in Egypt, Suez Desert Road, El Sherouk City \\ 2Institute for Materials Research and Innovation, The University of Bolton, Bolton \\ ${ }^{1}$ Egypt \\ 2U.K.
}

\section{Introduction}

In 2008 , total worldwide energy consumption was 474 exajoules $\left(474 \times 10^{18} \mathrm{~J}\right)$ with 80 to 90 percent derived from fossil fuels $(1)$. This is equivalent to an average power consumption rate of 15 terawatts $\left(1.504 \times 10^{13} \mathrm{~W}\right)$.

Most of the world's energy resources are from the sun's rays hitting Earth. Some of that energy has been preserved as fossil energy; some are directly or indirectly usable, for example via wind, hydro- or wave power. The term solar constant is the amount of incoming solar electromagnetic radiation per unit area, measured on the outer surface of Earth's atmosphere, in a plane perpendicular to the rays. The solar constant includes all types of solar radiation, not just visible light.

The estimates of remaining non-renewable worldwide energy resources vary, with the remaining fossil fuels totalling an estimated $0.4 \mathrm{YJ}\left(1 \mathrm{YJ}=10^{24} \mathrm{~J}\right)$ and the available nuclear fuel such as uranium exceeding 2.5YJ. Fossil fuels range from 0.6-3YJ if estimates of reserves of methane are accurate and become technically extractable.

The twentieth century saw a rapid twenty-fold increase in the use of fossil fuels. Between 1980 and 2006, the worldwide annual growth rate was $2 \%(1)$. According to the US Energy Information Administration's 2006, the estimated 471.8EJ total consumption in 2004 was divided as follows, with fossil fuels supplying $86 \%$ of the world's energy, see Figure 1 .

Coal fuelled the industrial revolution in the $18^{\text {th }}$ and $19^{\text {th }}$ century. With the advent of the automobile, airplanes and the spreading use of electricity, oil became the dominant fuel during the twentieth century. The growth of oil as the largest fossil fuel was further enabled by steadily dropping prices from 1920 until 1973.

\section{Literature review}

In today's world of sophisticated mechanical, electromechanical and electronic applications, polymers are playing an increasingly important part. One of the most significant advantages of polymeric materials over other materials is their complex structure, which can be physically or chemically tailored for specific applications. In year 2000, pioneering work carried out by HEEGER, MaCDIARMID and SHIRIKAWA on conducting polymers was rewarded with the Nobel Prize in Chemistry(2). 

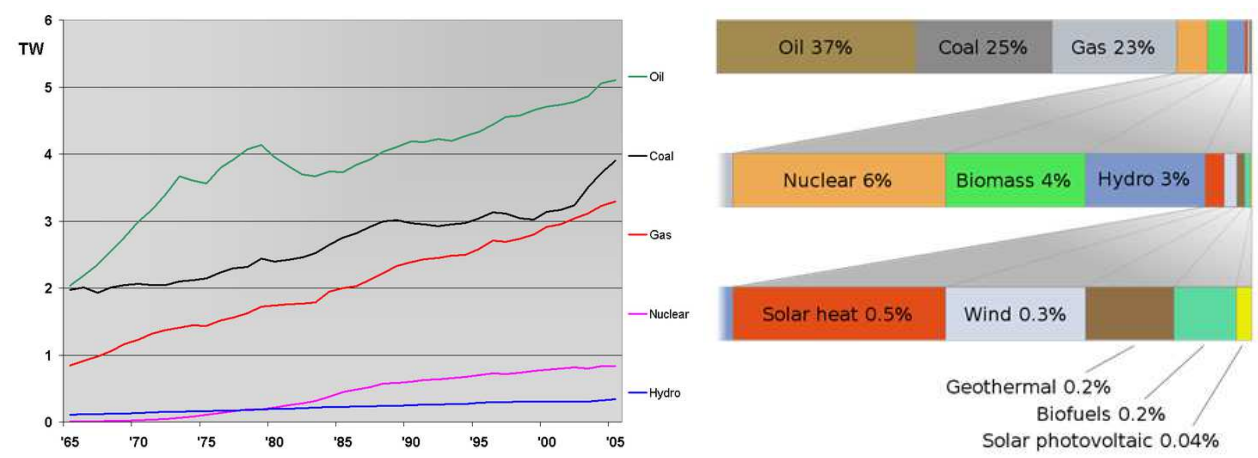

Fig. 1. Left, Rate of world energy usage in terawatts (TW), 1965-2005(1). Right, Global energy usage in successively increasing detail(1). Author of graph: Frank van Meirlo

Highly insulating polymers have been used extensively in electrical cable insulation since their invention in the first half of the $20^{\text {th }}$ century. Some fluoropolymers were shown to store injected electrical charges for long periods of time(3), even at elevated temperatures. The discovery of piezoelectric and pyroelectricity in polyvinylidene fluoride (PVDF) ${ }^{(4)}$ opened up wide market for electromechanical transducers applications. In recent years non-polar ferroelectrets ${ }^{(5)}$ with high piezoelectric coefficient have received a lot of attention. Already a new class of non- polar ferroelectrets based on charge storing polymers have become available in the market(6).

Reducing size and power requirements of wearable microelectronics can make it possible to replace batteries with smart systems that capture energy from the user's environment $(7)$. The consumer reliance on wearable electronic devices is growing significantly, which is leading to the demand for decreased size and enhanced capabilities of micro-power generation devices. Until now batteries have been sufficient, but a nuisance in terms of excess weight, rechargeability, replacement and disposal.

An average person spends a significant part of the day on foot, dissipating abundant energy into the soles of the footwear. This wasted energy could be harnessed in an unobtrusive manner to power a variety of low power application systems, such as pagers, health monitors, I-pods and possibly mobile phones. Studies at Massachusetts Institute of Technology (MIT) explored the feasibility of harnessing wasted energy from a variety of body sources, however, heel strike during walking has shown to be the largest untapped source of wasted energy(8). Scavenging most of the energy unobtrusively would be impossible, but a sizable fraction of it could provide sufficient energy to operate many of the personal micro-powered systems on the market today(9).

Another MIT study(10), as well as an independent work by ANTAKI et al(11) at another institution, supported and proposed a system of embedded piezoelectric materials and miniature controls. The research observed that a shoe having relatively large volume available in the sole would make an ideal test bed for exploring body energy harvesting. A recent development demonstrated the feasibility of scavenged shoe power using a simple application circuit ${ }^{(12)}$. The design is a self-powered radio frequency (RF) tag that transmits a short range 12bit wireless identification (ID) code during walking, see Figure 2. PVDF and PZT staves installed in the sole of the shoes. Previously, this area of work relied on battery powered IR badges(13), however, PVDF or PZT staves could be configured into the sole of the shoes to provide the required power for the signal to be transmitted. 


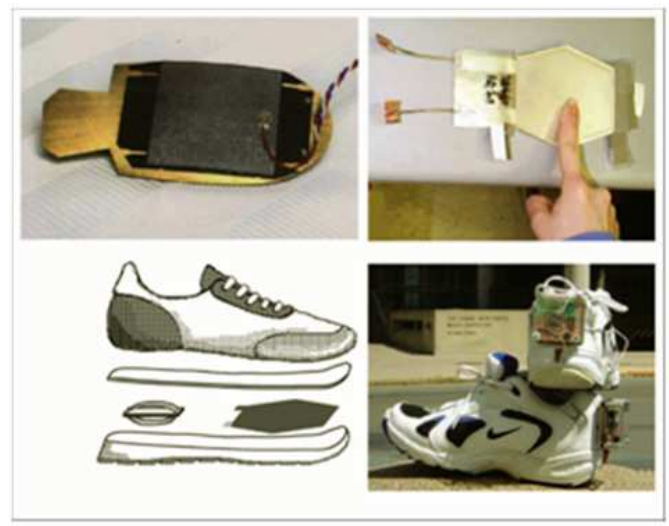

Fig. 2. PVDF and PZT staves installed in the sole of the shoes

It has been calculated that $5 \mathrm{~W}$ of electrical power can be generated by a $52 \mathrm{~kg}$ person at a brisk walking pace using a PVDF shoe insert(14). Similarly, another study used a free falling ball to impact a plate with a piezo-ceramic wafer attached to its underside, developed an electrical equivalent model of the PZT transforming mechanical impact energy to electrical power(15). This study also investigated the energy storage mechanism of the PZT with a bridge rectifier and a capacitor. Further studies examined use of a piezoelectric film in addition to ceramic-based piezoelectric material to provide power to light a bulb(16).

Since the discovery of piezoelectric properties, particularly of PVDF by KAWAI in 1969(17), piezoelectric polymer shaves been used in a wide range of sensor and actuator applications(18). PVDF has advantages over ceramic-based piezoelectric materials, in terms of mechanical flexibility, good acoustic coupling to aqueous media, and relatively low cost per unit area. A number of other polymers has been known to have potentially useful piezoelectric properties and these include some polymides(19), copolymers of vinylidene cyanide $(\mathrm{VDCN})(20)$, polyureas(21), polyurethane(22) and polythioureas(23).

\subsection{Introduction to Piezoelectricity}

A piezoelectric material has the unique ability to interchange electrical energy and mechanical strain energy or force. Due to this characteristic of the material, it has been found to be very effective for use in dynamic applications involving vibration suppression, mechanical impact and sensing. However piezoelectric materials have been used in numerous other applications including sonar application, audio buzzers, air ultrasonic transducers and piezoelectric ceramic ignition systems. While these materials have found notable applications, piezoelectric devices with a view to energy harvesting have not found the market that will allow the production rates of the materials to grow substantially and to become cost effective in other applications. As a result, a number of developments have emerged in the fields of harvesting or scavenging wasted energy, even from the human body i.e. from walking and the expansion and contraction of human lungs.

\subsubsection{Overview of the theory of Piezoelectric and Ferroelectrics}

Since the piezoelectric effect exhibited by natural materials such as quartz, tourmaline, rochelle salt, etc. is limited in terms of usable power, polycrystalline ferroelectric ceramic 
materials such as barium titanate $\left(\mathrm{BaTiO}_{3}\right)$ and lead zirconate titanate (PZT) with improved properties have been developed over the last few decades. Likes of PZT ceramic are available in many variations and are still the most widely used materials for actuator applications today. Prior to polarization mechanism, PZT crystallites have symmetric cubic unit cells. At temperatures below the Curie temperature, the lattice structure becomes deformed and asymmetric. The unit cells exhibit spontaneous polarization i.e. the individual PZT crystallites are piezoelectric.

A traditional piezoelectric ceramic is a mass of perovskite structure (material with the same type of crystal structure as calcium titanium oxide - $\mathrm{CaTiO}_{3}$ ), each consisting of a small, tetravalent metal ion, usually titanium or zirconium, in a lattice of larger divalent metal ions, usually lead or barium, and $\mathrm{O}_{2^{-}}$ions. Under conditions that confer tetragonal or rhombohedral symmetry on the crystals, each crystal has a dipole moment, see Figure 3.

To prepare a piezoelectric ceramic, fine powders of the component metal oxides are mixed in specific proportions then heated to form a uniform powder. The powder is mixed with an organic binder and is formed into structural elements having the desired shape (discs, rods, plates, etc.), for this research, a $120 \mu \mathrm{m}$ and $250 \mu \mathrm{m}$ diameter fibres were used. The elements are fired according to a specific time and temperature, during which the powder particles sinter and the material attains a dense crystalline structure. The elements are cooled, then shaped or trimmed to specifications, and electrodes are applied to the appropriate surfaces.
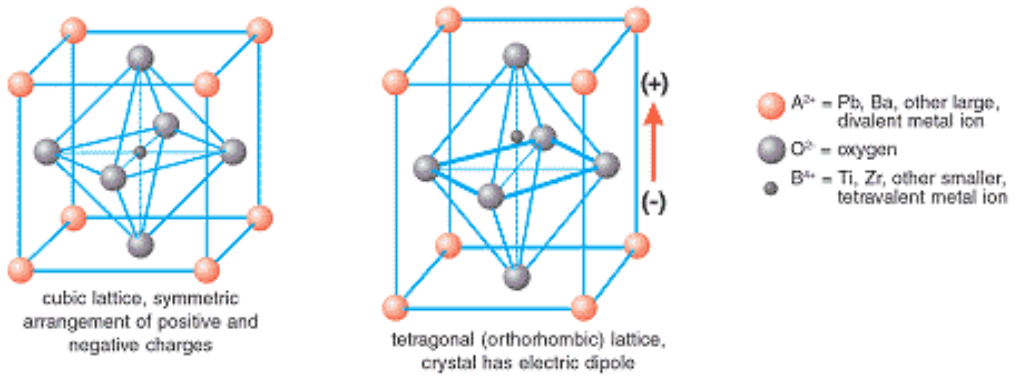

Fig. 3. Crystal structure of a traditional piezoelectric ceramic, left, temperature above curie point and right, temperature below curie point

Above a critical temperature, the Curie point, each perovskite crystal in the fired ceramic element exhibits a simple cubic symmetry with no dipole moment (Figure 3 left). At temperatures below the Curie point, however, each crystal has tetragonal or rhombohedral symmetry and a dipole moment (Figure 3 right). Adjoining dipoles form regions of local alignment called domains. The alignment gives a net dipole moment to the domain, and thus a net polarization. The direction of polarization among neighbouring domains is random, however, so the ceramic element has no overall polarization (Figure 4 left). The domains in a ceramic element are aligned by exposing the element to a strong, direct current electric field, usually at a temperature slightly below the Curie point (Figure 4 middle). Through this polarising treatment, domains mostly aligned with the electric field expand at the expense of domains that are not aligned with the field, and the element lengthens in the direction of the field. When the electric field is removed most of the dipoles are locked into a 
configuration of near alignment (Figure 4 right). The element now has a permanent polarization, the remnant polarization, and is permanently elongated.
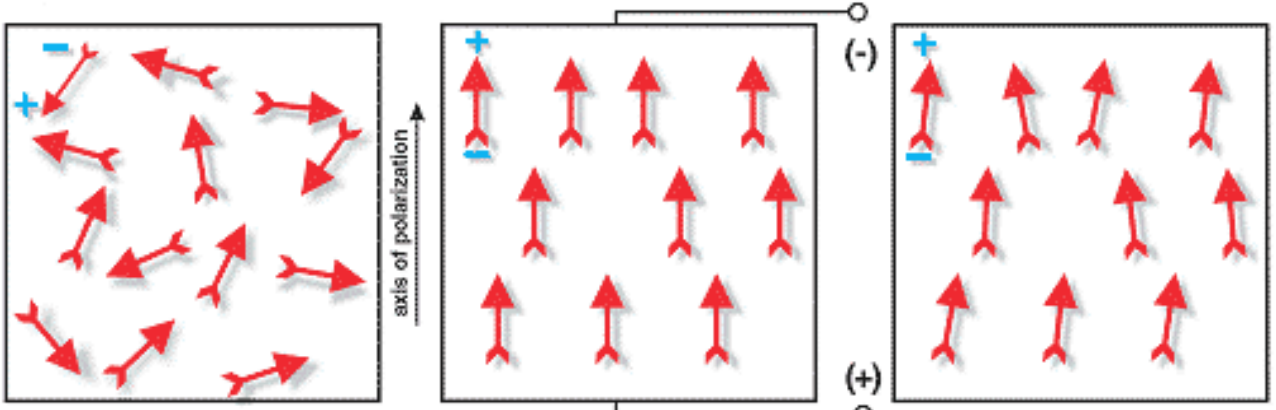

Fig. 4. Polarizing of a piezoelectric ceramic, left, random orientation of a polar domains prior to polarization, centre, polarization in DC electric field and right, remnant polarization after electric field is removed.

\subsubsection{Working of piezoelectric materials}

Mechanical compression or tension on a poled piezoelectric ceramic element changes the dipole moment, creating a voltage. Compression along the direction of polarization, or tension perpendicular to the direction of polarization, generates voltage of the same polarity as the poling voltage (Figure 5b). Tension along the direction of polarization, or compression perpendicular to the direction of polarization, generates a voltage with polarity opposite that of the poling voltage (Figure $5 c$ ). These actions are generator actions, where by the ceramic element converts the mechanical energy of compression or tension into electrical energy.

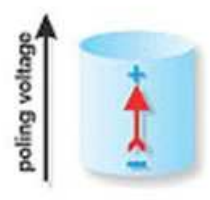
(a) disk after polarization (poling)

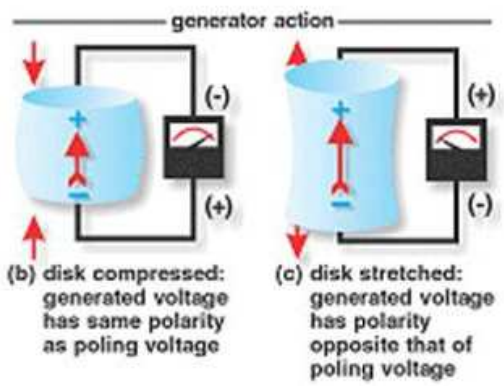

Fig. 5. Direct and indirect effect of piezoelectric material showing voltage generation when compressed and shape change when voltage is applied.

If a voltage of the same polarity as the poling voltage is applied to a ceramic element, in the direction of the poling voltage, the element will lengthen and its diameter will become smaller (Figure 5d). If a voltage of polarity opposite that of the poling voltage is applied, the element will become shorter and broader (Figure 5e). If an alternating voltage is applied, the element will lengthen and shorten cyclically, at the frequency of the applied voltage. This is 
motor action, where by electrical energy is converted into mechanical energy. The principle is adapted to piezoelectric motors, sound or ultrasound generating devices, and many other products. And it's this phenomenon which is exploited for energy, or voltage generation during various experiments that the piezoelectric materials are subjected to.

\subsection{History of piezoelectricity}

The very first experiments on the piezoelectric effect was performed on specially prepared crystals such as quartz, topaz, tourmaline, cane sugar and Rochelle salt by PIERRE and JACQUES CURIE in 1880(24). The findings were termed piezoelectricity, piezo from a Greek word meaning to press or squeeze and electricity is the end product. Whilst the CURIE brothers predicted and proved that electricity generated from applied stress to give the direct piezoelectric effect, they did not prove the converse effect. The converse effect (namely that application of electrical field creates a mechanical stress) was later mathematically proven by LIPPMAN in 1881 using the fundamental thermodynamic principles.

Although the piezoelectric discovery was a topic of great scientific interest, it was not until 1916 during WWI, PAUL LANGEVIN(49) produced the first engineering use for a piezoelectric material in a form of ultrasonic submarine detection.

Since the second world war, development of piezoelectric devices and materials in the United States has been kept within the companies doing the development. New materials were developed such as the quartz crystals which were the first commercially exploited piezoelectric material, but scientists searched for higher-performance materials. In contrast, Japanese manufacturers shared their findings, quickly overcoming technical and manufacturing challenges and creating new markets. Since late 60s, Japanese efforts in materials research created piezoelectric ceramic materials competitive to the U.S. materials, but free of expensive patent restrictions $(49)$. Major Japanese piezoelectric developments include new designs of piezoelectric ceramic filters for radios and televisions, piezoelectric buzzers and audio transducers that can connect directly to electronic circuits, and the piezoelectric igniters, which generate sparks for small engine ignition systems (and gas-grill lighters) by compressing a ceramic disc. Ultrasonic transducers that transmit sound waves through air had existed for quite some time, but first saw major commercial use in early television remote controls. These transducers now are mounted on several car models, helping the driver determine the distance from the rear of the car to any objects that may be in its path.

\subsubsection{Simple quantitative theory of piezoelectricity}

Piezoelectricity is a material property that is manifested when voltage is produced by applying mechanical forces, and vice versa, the effect has been described as direct and converse(25). Piezoelectricity has been described as coupling between a quasi-static electric field and dynamic mechanical motion. Equation (1) below represents constitutive(51) equation of linear piezoelectricity and is based on principle of energy conservation.

$$
\begin{aligned}
& \varepsilon=C \sigma+d^{T} E \\
& D=d \sigma+e E
\end{aligned}
$$


where $\sigma$ and $\varepsilon$ are stress and strain tensors that satisfy the condition of symmetry, respectively, and $D$ and $E$ represents electric flux density and the electric field, respectively. $C$ is the elastic compliance matrix, $d$ is the matrix of piezoelectricity coefficient, $d^{T}$ is the transpose of $d$ and $e$ represents the dielectric permittivity matrix. There are also other forms of linear piezoelectric constitutive equations which are given in the literature(26).

\subsection{Materials characteristics}

The decisive important property for the piezoelectric effect is the change of polarization when applying a mechanical stress. This might either be caused by a re-configuration of the dipole-inducing surrounding or by re-orientation of molecular dipole moments under the influence of the external stress. Piezoelectricity may then manifest itself in a variation of the polarization strength and its direction:

1. Orientation of dipoles within the crystal,

2. Crystal symmetry and

3. Applied mechanical stress

4. Intrinsic and extrinsic properties

Ceramic fibres in the diameter range of $10-250 \mu \mathrm{m}$ were used in a study(27). When formed into composite fibre they possess all the qualities of conventional block ceramic such as electrical, mechanical and chemical properties with additional advantages of light weight and flexibility. The piezoelectric fibre composites (PFC)(28) consist of unidirectional aligned piezoelectric fibres in an epoxy matrix, sandwiched between two copper clad polyimide laminates. The PFC devices have higher piezoelectric efficiency than traditional bulk piezoelectric ceramic materials, due to their large length to area ratio(17).

Typically, when in fibrous form, crystalline materials have much higher strengths and the polymer shell of the PFC allow the fibres to withstand impacts and harsh environments far better than monolithic piezoelectric ceramic materials. Table 1 shows a typical comparison values for the polymer and PZT based piezoelectric material. An energy harvesting system, using flexible fibre composite transducer, is capable of producing and storing typically $880 \mathrm{~mJ}(40 \mathrm{~V})$ of energy from a $30 \mathrm{~Hz}$ vibration over 13 seconds period.

\begin{tabular}{|c|c|c|c|}
\hline Property & Units & PVDF Film & PZT \\
\hline Density & $10^{3} \mathrm{~kg} / \mathrm{m}^{3}$ & 1.78 & 7.5 \\
\hline Relative Permittivity & $\varepsilon / \varepsilon_{0}$ & 12 & 1200 \\
\hline$d_{31}$ Piezoelectric Constant & $\left(10^{-12}\right) \mathrm{C} / \mathrm{N}$ & 23 & 110 \\
\hline$g_{31}$ Voltage Constant & $\left(10^{-3}\right) \mathrm{Vm} / \mathrm{N}$ & 216 & 10 \\
\hline $\begin{array}{c}k_{31} \text { Electromechanical } \\
\text { Constant }\end{array}$ & $\%$ at $1 \mathrm{KHz}$ & 12 & 30 \\
\hline Acoustic Impedance & $\left(10^{6}\right) \mathrm{kg} / \mathrm{m}^{2}-\mathrm{sec}$ & 2.7 & 30 \\
\hline
\end{tabular}

Table 1. Comparison of piezoelectric materials

Piezoelectric properties of porous PTFE foams have already been reported some time ago(29,30). The high surface charge stability of these materials in particularly elevated temperatures range has been confirmed $(31,32,33)$ and also in independent experiments $(34,35)$. To some extent, the stability of the surface potential and of the resulting piezoelectric response were found to improve with increasing porosity to some extent(23). For a single PTFE foam film, a high piezoelectric coefficient was found(36), but the effect decreased by a factor of 2 
when uncharged PTFE films were inserted between the charged films and the electrodes(37). Consequently, single layer foams were studied and it became clear that part of the piezoelectric effect in this case stems from change in the air gaps between porous electret and disk electrodes(27,38).

Further work has been conducted where PTFE foam layers have been incorporated into multilayered sandwiches(26,39), i.e. double layer sandwiches of one hard and one soft layer with an interface charge layer between them $(40,41,42)$. If two or more separate foams are to be assembled into such a sandwich, then air pockets have to be avoided.

Since the discovery of piezoelectric $\operatorname{PVDF}(43)$, it has been widely used in a range of sensors and actuator applications ${ }^{(44)}$. In addition, several other polymers have been shown to have potentially useful piezoelectric properties, such as polyamides(45), copolymers of vinylidene cyanide $(\mathrm{VDCN})^{(46)}$, polyureas ${ }^{(47)}$ and polyurethane $(\mathrm{PU})^{(48)}$ mainly due to their lightweight and flexibility. The two layer approach has been investigated with the polypropylene (PP) and PU foams ${ }^{(49)}$, whilst further research has been investigated on stacks of corona-charged porous and non-porous PTFE(50) and reported piezoelectric $d_{33}$ coefficient values of up to $35 \mathrm{pC} / \mathrm{N}$ and as high as $150 \mathrm{pC} / \mathrm{N}$ has been obtained with single layer of porous PTFE(51).

Cellular PP foams are usually produced in a modified blow extrusion process $(52,53)$. Prior to foam blowing, spherical voids of approximately $10 \mu \mathrm{m}$ are generated by gas injection into the polymer melt. The melt is extruded, cooled down and reheated for foam blowing. Foam formation is accompanied by biaxial orientation, which results in disk or lens shaped voids(54). In addition, most cellular PP foams have co-extruded outer layer of non voided polymer for higher surface smoothness, better thickness uniformity and improved electrode adhesion(55). Charging of PP is done by means of corona charging with high corona point voltages around $20 \mathrm{kV}^{(36,56)}$.

The resulting surface charge leads to high electric fields across the thickness of the foam and thus internal breakdown in disk-shaped voids(57,58,59). After breakdown, the voids are charged to top and bottom polarities that are opposite to respective surface charge and electrode polarities of the foam(37). In addition to corona charging, electrode charging $(60,61,62)$ and electron beam charging(63) have been reported. Figure 6 below depicts the typical microstructure of PP foam.
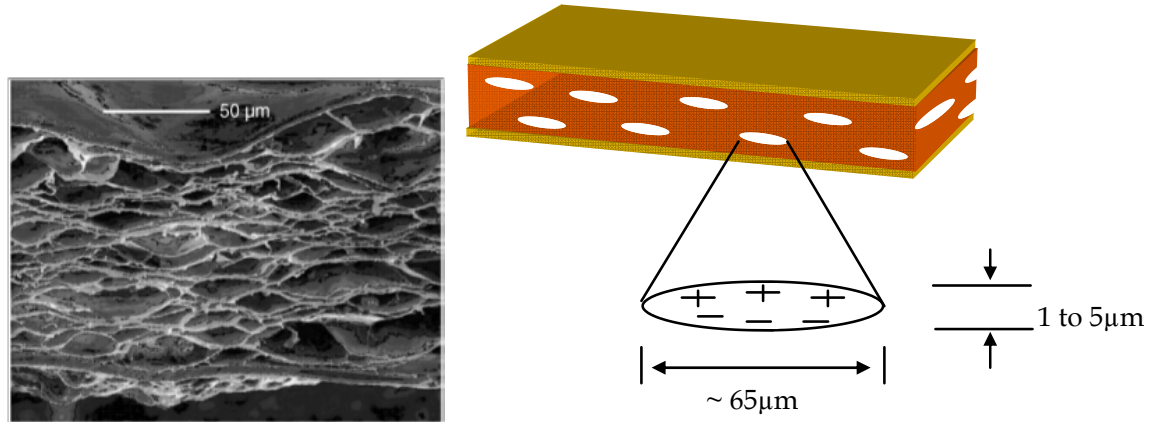

Fig. 6. SEM and schematic diagram of PP foam with elliptical voids

\subsection{Poling methods}

In order to understand the microscopic mechanism of charge storage, it is important to understand the characteristics of fundamental material parameters as well as the 
measurement of specific sample or device properties. Progress in the area of electrets research has been widely enhanced with the wide range of methods to characterise them with respect to their electrical, thermal, mechanical and chemical properties. To date, several characterisation techniques have been developed.

Over the past three decades, several techniques for obtaining space charge and polarisation depth profiles in insulating materials have been developed(64). These methods have been applied to a number of areas, such as accumulation of space charge in high voltage cable insulations $(65)$, the development and optimisation pyroelectric and piezoelectric sensors $(66,67)$ and basic research into mechanisms of charge storage ${ }^{(68)}$ in electret polymers.

\subsection{Production of PZT fibres}

The nature of the ceramic monolithic piezoelectric material makes them brittle and vulnerable to accidental breakage during handling and bonding procedures as well as in the service intended. In addition, they have poor ability to conform to curved surfaces and are very dense and stiff causing mass loading and localized stiffness. These limitations have encouraged researchers to develop alternative methods of manufacturing the piezoelectric ceramics in order to make them more suitable for the next generation of piezoelectric applications.

In order to resolve the inadequacy of the monolithic piezoelectric ceramic material for many applications, the idea of using a composite material consisting of an active piezoelectric ceramic fibrous phase embedded in a polymeric matrix phase has been investigated by a number of researchers. In addition to this added strength of the base material, the flexibility of the polymer matrix allows the piezoelectric ceramic fibres to have greater conformability to curved surfaces and provides a protective shell around the piezoelectric material. This polymer shell allows the piezoelectric-fibre to withstand impacts and harsh environments far better than monolithic piezoelectric materials. The result of configuring the piezoelectricfibre inside a polymer matrix is an actuator that can be incorporated into or bonded to more realistic structures.

This soft moulding process holds many advantages over the previously used die-and-fill, injection moulding or dicing techniques due to the moulds being reusable, allowing thousands of identical actuators to be made. In addition, the fabrication is relatively easy and cost effective because of the simplicity of the mould construction when compared to the other options for fibre construction. Once the brittle fibres are formed a polymer matrix is added to the remaining spaces to protect the fibres from breakage. Subsequent to this process is the addition of metal electrodes for poling of the device, later to be used as a means of applying an electric field or measuring the current produced during sensing. Piezo ceramic fibres have been produced through a patented injection moulding process(69). The procedure combines PZT powder with a wax-based binder, and then the material is granulated as feedstock for the injection moulding process. Once this is completed the feedstock is heated to the specified viscosity and rapidly injected at high pressure into a cooled mould. Due to the incompressible nature of the material, when injected into the mould the fibres obtain a constant density throughout and remove of voids and internal defects that occur during dry pressing or low pressure forming methods. The homogeneous density of the material produces uniform microstructures, dimensions and electromechanical properties after firing.

After the production of the piezoelectric ceramic fibres an electrode layer is placed on the top and bottom of the fibres to facilitate the application of an electric field for the collection 
of current during sensing. The Active Fibre Composite (AFC) uses inter-digitised electrodes that allow the electrical potential to form along the length of the fibre; therefore capitalizing on the higher $d_{33}$ piezoelectric coupling coefficient. A schematic diagram to illustrate the electric field developed along the fibres is shown in Figure 7. The metallic electrodes are normally formed using photolithography, which is a very precise process, however it is a time consuming and expensive process that etches copper strips onto a thin Kapton ${ }^{\circ}$ film.

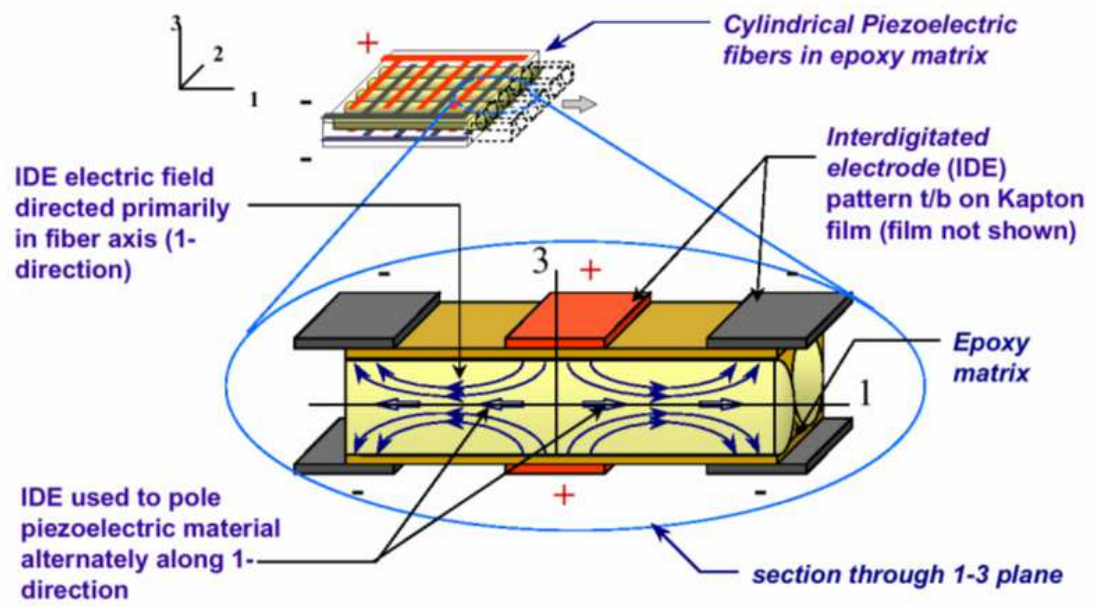

Fig. 7. Schematic of the cross section of an AFC actuator(164)

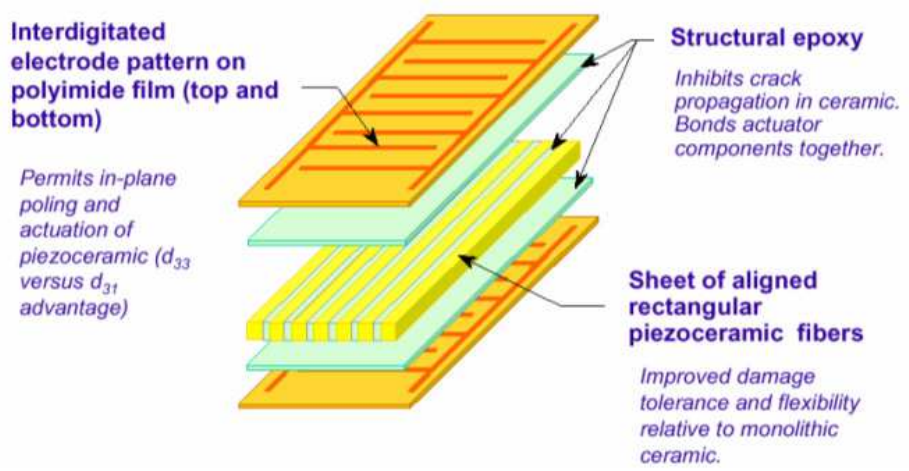

Fig. 8. Schematic showing the order of different layers in the macro-fibre composite actuator.

The final product is an actuator that has increased flexibility, durability and electromechanical coupling due to the inter-digitated electrodes that capitalize on the higher $d_{33}$ coefficient. This type of technology has many possible structural applications; however, the assembly can be avoided and the fibre can be incorporated directly into any laminated composite material. One of the major considerations for the use of this property is to incorporate the fibres into the rotor blades of a helicopter. The helicopter blades experience 
large aerodynamic loads and in turn induce large vibration and noise issues(162). With the active fibre embedded inside the rotor blade the vibration and noise levels inside the helicopter could be significantly reduced providing increased comfort to the pilot and passengers of the aircraft. The layers of the MFC are shown in Figure 8. However, the MFC has one difference that greatly affects the manufacturing process and the performance of the actuator, it has rectangular fibres.

\subsection{Production of PVDF Films}

Rolls of piezoelectric PVDF film are produced in a clean room environment. The process begins with the melt extrusion of PVDF resin pellets into sheet form, followed by a stretching step that reduces the sheet to about one-fifth its extruded thickness. Stretching at temperatures well below the melting point of the polymer causes chain orientation of the molecules into parallel crystal planes. These are called "beta phase" materials. To obtain high levels of piezoelectric activity, the beta phase polymer is then exposed to very high electric fields to align the crystallites relative to the poling field(70).

Copolymers of PVDF are polarisable without stretching. Evaporative deposited metals are typically 500 to $1000 \AA$ in thickness, and almost any metal can be deposited. Popular metals are nickel, aluminium, copper, gold and alloys. Electrode patterns are made by sputtering through masks or by chemical etching continuous metallization using photo resists. Resolution to $25 \mu \mathrm{m}$ line widths has been achieved. Screen printed electrodes of conductive silver ink are much thicker, about $5-10 \mu \mathrm{m}$, and can be applied in complex patterns to form multiple sensors on a single sheet. Foils are adhered with thin adhesive layers coupled to the piezoelectric film(165).

Generally, sputtered metals are for very high resolution arrays, pyroelectric applications requiring a low thermal mass, or for inertness, as with invasive medical applications. Fully metallised sheets can by carefully cut with a razor blade without shorting across the film thickness. Screened inks are very robust and compliant, withstand very high strains $(>10 \%)$, can operate at high voltages without breakdown, and are easy to pattern on a continuous basis. However, un-metallised borders are required for cutting elements out of a sheet of screen printed electrodes, since there is a high likelihood of shorting across the films thickness with the thick inks. Foils may mechanically restrict the piezoelectric film from responding to externally applied stresses and strains in the plane of the film, but foils are useful in pure "thickness mode" operation(165).

After metallization, a wide variety of possible processing steps are followed to produce a packaged sensor. Generally, the piezoelectric film is laminated in a protective carrier then die cut to size, and packaged with lead wires or crimp connectors(165).

\subsection{Production of PP foams}

An electromechanical film is a thin porous PP film with biaxially oriented flat voids, with a lateral dimension of $10 \mu \mathrm{m}$ to $100 \mu \mathrm{m}$ and a vertical dimension of $1 \mu \mathrm{m}$ to $5 \mu \mathrm{m}(71)$, as shown in Figure 6. This internal structure is obtained through extrusion, biaxial stretching, and controlled inflation by patented pressure treatments(72). Under the effect of high electric field, during the manufacturing process, the heterogeneous foam film acquires a permanent space-charge, with the upper surface of the gas voids with the polarity opposite to the lower surface. The charged voids become perfectly oriented quasi-dipoles, as shown in Figure 9(73). These artificial dipoles are responsible for the macroscopic piezoelectric behaviour of these cellular polymers. 


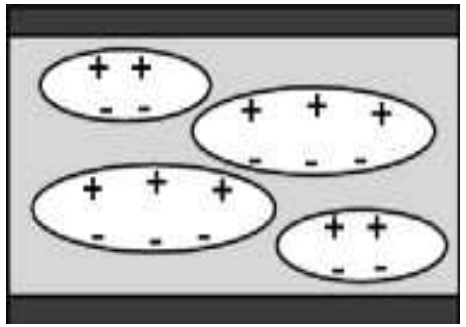

Fig. 9. Charged voids in the foam (which produce the quasi-piezoelectricity) represent the structure and the inhomogeneous charge distribution.

The transducer is obtained after evaporating or gluing electrodes to the external faces of the charged-foam film. From the application point of view, it is important to take into account that if the metal coating or the glue is too rigid, the piezoelectric response of the film (a charge) will be small, causing a shift of the piezoelectric resonance peak(74).

In summary, ferroelectrics polymers have some advantages compared to conventional piezoelectric materials based on ceramics or polar polymers. Apart from being thin and lightweight, the polymer piezoelectric material have high $d_{33}$ coefficients, and may be obtained in almost any size and/or shape. They can be easily handled and they are low cost. Their relatively small specific acoustic impedance is an advantage for many transducer applications. Nevertheless, their main drawback is the reduced stability of the piezoelectric effect at temperatures over $50^{\circ} \mathrm{C}$, and this can limit their application range.

\subsection{Piezoelectric applications}

Electret condenser microphones are still the most widely used applications for charge storing polymers, however, a number of other publications $(75,76)$ have demonstrated the feasibility of using inorganic $\mathrm{SiO}_{2}$ layers or $\mathrm{SiO}_{2} / \mathrm{SiO}_{3} \mathrm{~N}_{4}$ double layers as charge storing membranes. Generally, polymers are the materials of choice for large scale pyroelectric and piezoelectric applications. The main drawbacks of ferroelectric polymers as compared to ceramic materials are their relatively low piezoelectric and pyroelectric coefficients.

Significant advances have been realized in an effort to increase the piezoelectric coefficient of polymer films when results from electric dipoles at a macroscopic, rather than molecular level were considered. For example, KACPRZYK elaborated on a two-layer system of corona charged PP and PU films(77), and GERHARD-MULTHAUPT et al. investigated stacks of corona charged porous and non-porous $\operatorname{PTFE}(78)$ and reported piezoelectric $d_{33}$ coefficient of up to $35 \mathrm{pC} / \mathrm{N}$. Even higher values of up to $150 \mathrm{pC} / \mathrm{N}$ were obtained by KUNSTLER et al. with single layers of porous PTFE carrying a bipolar space charge(79). However, most significant new class of cellular space charge electrets is based on a concept reported by KIRJAVAINEN(80).

Voids are created by means of biaxially stretching a composite film consisting of a PP polymer host and inorganic fillers. After inflation, typical void dimensions are $30 \mu \mathrm{m}$ to $100 \mu \mathrm{m}$ in diameter and approximately $1 \mu \mathrm{m}$ to $5 \mu \mathrm{m}$ in height can be achieved. Similar films are also extensively used in the packaging industry, where the micro voids serve both as thermal insulation and give the polymer film an attractive glossy look(81). Subjecting these films to high electric fields is thought to initiate breakdown, with subsequent charge separation and charge trapping on the inner surface of the voids. This is supported by several recent experimental observations. 
Micro discharges have been observed through their luminescence(82,83), and the bipolar charge distribution was visualized via the secondary emission yield in a SEM(84). The induced microscopic polarization can be reversed by applying a sufficiently high electric field in the opposite direction(173) (a characteristic of ferroelectric material). Furthermore, electrical and electromechanical hysteresis was also observed(85), although this behaviour was recently shown not to be related to the polarization, but rather results from interfacial charge injection and charge generation by external gas discharges at the electrode edges(86). As a result of their piezoelectric properties and switchable polarization, both of which are characteristic properties of ferroelectric materials, the term ferroelectrets has also been used(175).

Applying a mechanical stress to foam materials changes the vertical dimensions of the voids and therefore the dipole moment of the separated positive and negative charges trapped on the internal surfaces of the voids, resulting in macroscopic polarization changes, giving rise to a qausi-piezoelectric response. As these polymer foams are relatively soft perpendicular to their film plane, the resulting piezoelectric $d_{33}$ coefficients are at least 1 order of magnitude larger than those found in conventional ferroelectric polymers, such as PVDF(87). Through charging in a suitable dielectric gas atmosphere at elevated pressure(88), these coefficients were increased up to $790 \mathrm{pC} / \mathrm{N}$. The shape of the cavity can be optimized by means of a gas inflation treatment( ${ }^{(89)}$, resulting in even higher coefficient of up to $1500 \mathrm{pC} / \mathrm{N}(90,91)$. Biaxially stretched polymer foams are highly anisotropic, and as a result, exhibits large $d_{33}$ coefficients but relatively small $d_{31}$ values and little pyroelectricity(92).

Based on these piezoelectrets, several applications for large area transducers have been suggested and some are already commercially available. For example, using large mats of these films it is possible to monitor the motion of people and even identify individuals(93) based on single footsteps. Cellular PP foams have also been used for monitoring physiological processes in humans and animals( ${ }^{94)}$. Another promising area of applications is active vibration and noise control(95). Numerous transducer applications have been suggested, demonstrated, and commercialized with different kinds of piezoelectric materials ${ }^{(96)}$. They cover a broad frequency range from quasi-static applications to the audio, super-audio, and ultrasound frequency range. Cellular polymers may find their niches in several of these applications, where the low cost and large-area processing of such polymers are advantageous. Therefore, cellular polymers have attracted a lot of interest in engineering studies, but they are not without their disadvantages( ${ }^{(97)}$.

\subsubsection{Sensors for motion control and pressure measurement}

Detection of motion control, for example, the traffic on the roads or the motion of humans in houses or factory buildings for medical or for safety observations is usually performed by video cameras, infrared detectors, or individual piezoelectric sensors. By placing cellular polymer films on the ground, surveillance of rooms and of the surrounding of machines can be easily achieved(98). Due to the high transducer sensitivity it is possible to place the sensor film underneath different floor coatings such as polymers, woods, ceramics, or stones(194).

Pressure measurements with cellular polymers can also be used in sports facilities to optimize the training of athletes. One example is the implementation of cellular piezoelectric transducers in ski jumping, where cellular polymers allow for the force measurement during the jumpers takeoff ${ }^{(99)}$. Besides the monitoring of the pressure distribution on a floor, the pressure distribution in soles of shoes, for example, can be determined during running or walking $(194,100)$. 
For orthopaedic diagnostics, pressure monitoring on seats and backrests is very interesting, too. The results could lead to further optimization of office chairs or of seats in cars, trains, and aircraft. The sensitivity of cellular polymer transducers is also high enough for recording the respiration of human patients, even if the transducers are not directly fixed to the skin of the patient(101). Sensors made of cellular PP have been placed directly on the bed for long-term respiration monitoring. Usually, the sensor signals measured during the movement of the patient are superimposed on the respiration signal. Cellular polymer films also allow for measuring pressure distributions within the body itself.

\subsubsection{Control panels and keyboards}

Push buttons for keyboards, keypads, and control panels with small areas have been made with cellular piezoelectric polymer films. Keypads are commercially produced by the Screentec company in Finland, and are used for example, in interfaces for information systems in public transportation or as access readers for different applications ${ }^{102)}$. The high sensitivity allows the implementation of the sensors behind protective layers of different materials (with a thickness up to $5 \mathrm{~mm}$ ) to achieve vandal-proof control panels usable for cash dispensers and ticket machines or other systems in public transportation(201,103).

Based on soft and flexible polymer films, the construction of flexible keypads or keypads covering any shape, see Figure 10. In the long run, flexible keypads including electronic circuitry may become a reality, since organic electronic circuitry is rapidly developing towards commercialization. A mechanical pressure on one of the push buttons with a load of, for example, $2 \mathrm{~N}$ leads to a sensor voltage signal of around $200 \mathrm{mV}$ with a rise time of only $30 \mathrm{~ms}$, which is easily detected with standard electronics.

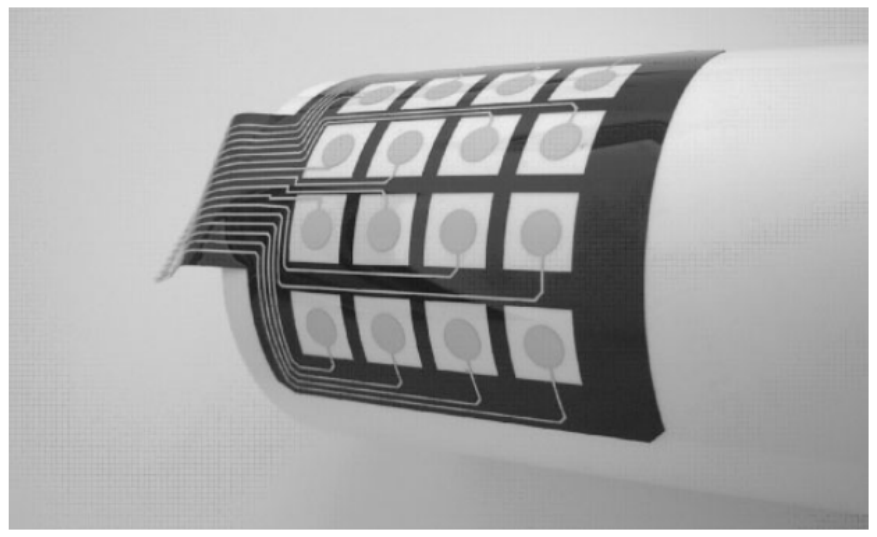

Fig. 10. Schematic sketch of a curved sensor arrangement(201)

\subsubsection{Electro acoustics}

There is a large potential for applications of internally charged cellular ferroelectrets in electro acoustic applications, where the frequency range from the audio to the ultrasound can be spanned. Microphones and especially pickups based on cellular PP sensors are already on the market, produced by the companies Emfit Ltd. and B-Band Ltd. in Finland(195,104). The commercial pick-ups show a bandwidth from $50 \mathrm{~Hz}$ to $23 \mathrm{kHz}$, a low distortion of $0.05 \%$, and a good signal-to-noise ratio exceeding $90 \mathrm{~dB}$. 
Based on optimized preparation methods including the formation of multilayer stacks, the sensitivity could be increased significantly(105). Piezoelectric coefficients between $100 \mathrm{pC} / \mathrm{N}$ and $1000 \mathrm{pC} / \mathrm{N}$ are now routinely achieved, depending on the preparation technique, thereby increasing the microphone sensitivity by a similar level(106). Cellular polypropylene films can also be used as microphones in the super audio frequency range(212) up to $40 \mathrm{kHz}$. A bandwidth exceeding $315 \mathrm{kHz}$ was demonstrated, thereby opening routes for the detection (and generation) of airborne ultrasound(107). However, the strong sensitivity to pressure changes limits the use of cellular polymer hydrophones to shallow-water applications.

\section{Experimental methodology and materials}

In order to establish and compare the voltage output for all 3 piezoelectric materials, initially, vibration experiments were carried out using an electro mechanical shaker. The electro mechanical shaker vibrated the attached plastic ruler which had the piezoelectric material attached on the top surface of the ruler, frequency range from 0 to $120 \mathrm{~Hz}$ were selected. The second part of the vibration experiment consisted of manually vibrating the piezoelectric materials using a metallic and plastic platform and comparing the energy outputs. Finally, this chapter will also compare and discuss the results output for all 3 piezoelectric materials when subjected to impact forces from a given height using $4.9 \mathrm{~g}, 11.9$ and $1.02 \mathrm{~kg}$ mass using a free fall height experimental set up and a fixed structure.

Optical microscopy will be performed on the PZT-based $125 \mu \mathrm{m}$ piezoelectric material and Scanning Electron Microscope (SEM) will be carried out on the rest of the piezoelectric material to establish and verify manufacturers specifications.

\subsection{Materials investigated}

There are two common piezoelectric materials - polymer based PVDF and ceramic based PZT. The polymer materials are soft and flexible; however, they possess lower dielectric and piezoelectric properties than ceramics. Conventional piezoelectric ceramic materials are rigid, heavy and can only be produced in block form.

A variety of piezoelectric materials have been used in this study. Two ceramic materials, with active piezoelectric fibres of $250 \mu \mathrm{m}$ and $120 \mu \mathrm{m}$ diameters were embedded in a polymer matrix and encapsulated in copper-clad laminate, see Figure $\mathbf{1 1}$ left and Table 3. A ceramic so called bimorph material consisting of two $250 \mu \mathrm{m}$ fibre diameter materials adhered to either side of a rigid metal centre shim material.

Laminated piezoelectric polymer material, PVDF, where two $125 \mu \mathrm{m}$ polyester laminates were bonded either side of a $28 \mu \mathrm{m}$ thick piezoelectric film element $(28 \mu \mathrm{m}$ laminate), two unlaminated PVDF materials of $28 \mu \mathrm{m}$ and $52 \mu \mathrm{m}$ thicknesses $(28 \mu \mathrm{m}$ and $52 \mu \mathrm{m}$ un-laminated, respectively), see Figure $\mathbf{1 1}$ middle and Table 2.

Finally, a fully shielded, low mass, thin ribbon PP sample was used. The sample consisted of a sensing element constructed of elastic electret, 3 layers of polyester film. Aluminium electrodes with crimped connectors were used for connecting to electrodes and doublesided sticky tape for convenience, see Figure 11 right and Table 2.

The dimensions and classification of the piezoelectric polymer and ceramic materials are given in Tables 2 and 3, respectively. The piezoelectric PZT fibre composites were obtained from Advanced Cerametrics Incorporated (ACI)(108). The PVDF polymer films were manufactured by Measurement Specialities Incorporated (MSI)(109) and piezoelectric PP polymer foam as manufactured and supplied by Emfit. 


\begin{tabular}{|c|c|c|c|}
\hline Material & $\begin{array}{c}\text { Sample } \\
\text { Width (a) } \\
(\mathrm{mm})\end{array}$ & $\begin{array}{c}\text { Sample } \\
\text { Length (b) } \\
(\mathrm{mm})\end{array}$ & $\begin{array}{c}\text { Sample } \\
\text { thickness } \\
(\mu \mathrm{m})\end{array}$ \\
\hline $28 \mu \mathrm{m}$ laminated PVDF (LDT1-28 $\mu \mathrm{m})$ & 16 & 41 & 205 \\
\hline $28 \mu \mathrm{m}$ laminated PVDF (LDT2-28 $\mu \mathrm{m})$ & 16 & 73 & 205 \\
\hline $28 \mu \mathrm{m}$ laminated PVDF (LDT4-28 $\mu \mathrm{m})$ & 22 & 171 & 205 \\
\hline $28 \mu \mathrm{m}$ un-laminated PVDF (DT4-28 $\mu \mathrm{m}$ ) & 22 & 171 & 40 \\
\hline $52 \mu \mathrm{m}$ un-laminated PVDF (DT4-52 $\mu \mathrm{m})$ & 22 & 171 & 70 \\
\hline $65 \mu \mathrm{m}$ laminated PP & 200 & 100 & 320 \\
\hline
\end{tabular}

Table 2. Characteristics of Piezoelectric PVDF and PP Materials Used

\begin{tabular}{|c|c|c|c|}
\hline Material & $\begin{array}{l}\text { Sample width (c) } \\
(\mathrm{mm})\end{array}$ & $\begin{array}{l}\text { Sample Length }(\mathrm{d}) \\
(\mathrm{mm})\end{array}$ & $\begin{array}{l}\text { Sample thickness } \\
(\mu \mathrm{m})\end{array}$ \\
\hline $120 \mu \mathrm{m}$ fibre & 15 & 140 & 190 \\
\hline $250 \mu \mathrm{m}$ fibre & 15 & 140 & 320 \\
\hline $250 \mu \mathrm{m}$ fibre Bimorph & 15 & 140 & 750 \\
\hline
\end{tabular}

Table 3. Characteristics of Piezoelectric PZT Materials Used

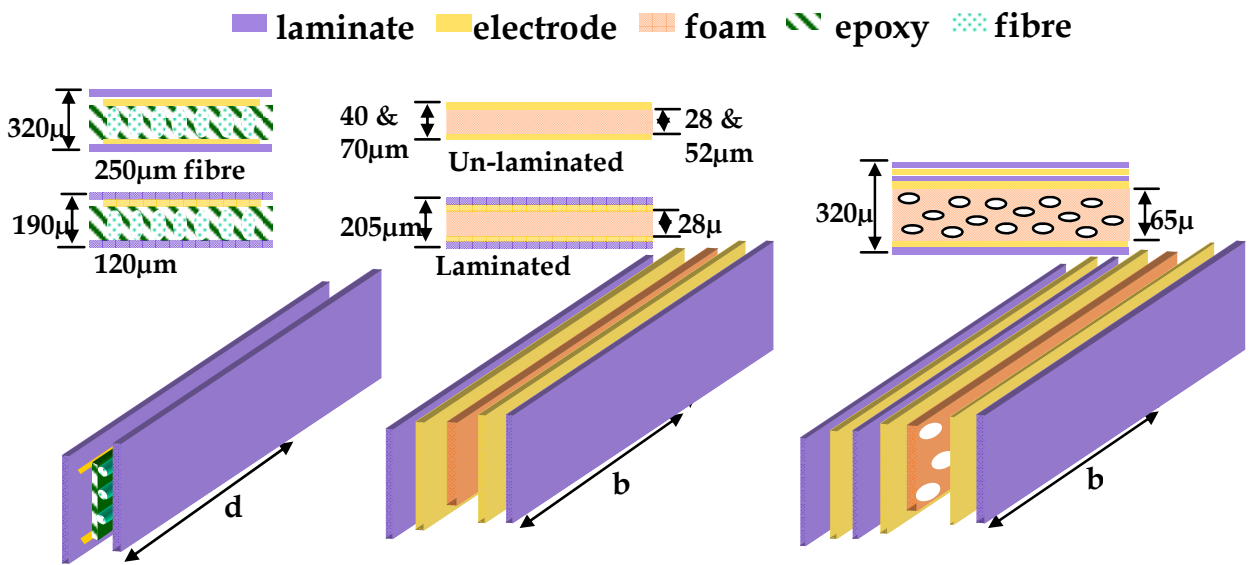

Fig. 11. Schematic representation of non symmetrical piezoelectric samples, left,

Piezoelectric PZT fibre embedded in an epoxy with copper clad electrodes etched on to the inner surface of the laminate which acts as electrodes, middle, PVDF membrane film and right, porous PP with pores (app. $10 \mu \mathrm{m}$ diameter).

Ceramic materials add additional mass and stiffness to the host structure, especially when working with flexible/lightweight materials. This and their fragile nature limit possibilities for wearable devices, whereas the polymer membrane and the foam are very versatile, cost effective and able to conform to intricate shapes and designs.

This work has directly compared PZT, PVDF and PP piezoelectric materials for their ability to generate energy in terms of voltage output. Each category of material behaved differently under varying conditions. The initial vibration experiments using electro mechanical shaker and frequency between $0-120 \mathrm{~Hz}$ have shown that the single layer of PZT $120 \mu \mathrm{m}$ and $250 \mu \mathrm{m}$ 
produced larger voltage output when compared with the double layer structures. However, this could have been due to inadequate bonding between the multilayer specimens. Similar conclusions can be drawn from the results for the single and multilayer PVDF specimens subjected to the same experimental procedures.

\section{Conclusion and future work}

Several experiments were conducted in order compare and contrast the voltage output between the PZT and PVDF piezoelectric material. Overall, the PZT bimorph produced largest voltage output under all experimental conditions, followed by the single layer $250 \mu \mathrm{m}$ sample and $120 \mu \mathrm{m}$ single layer specimen. PVDF based structures produced the lowest voltage output under these conditions.

Under impact testing using $4.9 \mathrm{~g}$ and $11.9 \mathrm{~g}$ mass from a fixed height, it was again shown that the PZT $250 \mu \mathrm{m}$ single layer specimen produced higher voltage output when both masses were dropped independently on to the specimen. However, PZT $120 \mu \mathrm{m}$ displayed the opposite effect, where the double layer generated marginally higher voltage in comparison to single layer. This could be due to the inconsistencies within the supplier batch of the material, as well as the lack of efficiency of bonding within the multilayer structure. In any case, the heavier mass i.e. 11.9g delivered larger voltage outputs for all the PZT and PVDF piezoelectric materials due to larger surface area contact between the heavier mass and the surface of the specimen, and the generating larger striking force.

In order to establish whether impact at various positions of the sample delivered any effect, the samples were subjected to impact analysis using an Instron machine with $1.02 \mathrm{~kg}$ mass striking the sample on both ends and at the centre. No significant variation in the voltage output was observed due to the positional impact for most of the samples. However, for the PZT Bimorph structure the voltage output was three times greater when the impact was made at the edges than values obtained for the central impact. This is due to the presence of the metal shim between the layers, which produced additional vibrations within the structure. On the other hand the impact at the centre of the material may also have resulted in cancellation of the out-of-phase vibrations.

Notable variations were recorded for 3 of the 4 batches of the same PVDF material i.e. LDT1$28 \mu \mathrm{m}$ (smaller laminated) piezoelectric sample subjected to similar analysis. The higher voltage output was associated with the edge closest to the positive and negative terminals. This level of variation was evident for all PVDF configurations.

Controlled vibration of PZT and PVDF materials in contact with a flexible ruler indicated that generally, the metallic ruler provided largest amount of energy due to the better vibration properties compared with the plastic ruler. Again, PZT bimorph specimen displayed the largest voltage output out of the three materials investigated. It was also found that, generally, as the distance of the specimen from the fixed edge increased so did the voltage resonance and the collective total voltage output.

During temperature elevation experiments, it was found that as the temperature increased, the voltage output dropped for the PZT material, whereas the converse effect was observed with PVDF. This appears to be possibly due to reversion of the PZT material back to the post piezoelectric state, particularly as the polymer matrix in which the PZT piezoelectric fibres are embedded and consequently aids the temperature increase of the structure. As for the PVDF, the internal chains $-\left(\mathrm{C}_{2} \mathrm{H}_{2} \mathrm{~F}_{2}\right)_{\mathrm{n}}$ are excited and become more mobile, hence, delivering voltage at an increased rate. 
The subzero temperature experiment (from room to approximately $-30^{\circ} \mathrm{C}$ ) showed some interesting phenomena in terms of voltage output. For all of the three piezoelectric materials, energy output generally increased as the temperature began to drop. This may be the result of material shrinkage at sub-zero temperatures - causing compaction of the atoms with within the material and therefore increasing the efficiency of electron transfer processes.

All three materials showed positive and negative attributes in terms of energy output depending on the conditions. In terms of maximum voltage output, the PZT Bimorph specimen generated largest voltage output, however, at a cost of increased weight, lack of flexibility and due to additional manufacturing and production costs. The application PZT piezoelectric material will not be suitable at elevated temperature due to reverse polarisation process and the very nature of the fragile fibres.

The work reported in this thesis highlighted many aspects of various piezoelectric materials and their commercial and domestic applications. This research was aimed at comparing the 2 variants of piezoelectric materials, namely PZT-based and PVDF-based piezoelectric under normal room temperature, elevated and sub-zero temperatures. This work has opened many opportunities for future work, particularly in-house production of these materials which will provide huge flexibility. Future work will provide good opportunities to develop piezoelectric materials/structures with enhanced flexibility and voltage output of several magnitudes higher than those reported to date.

So far we have investigated piezoelectric materials which are produced by particular manufacturers with standard sizes of the specimen and limited material configurations. In terms of PZT, the piezoelectric materials that were available at the time were limited to $120 \mu \mathrm{m}$ and $250 \mu \mathrm{m}$ fibre diameters - as a single layer, bimorph and 4 layer structures. The future work should incorporate various fibre diameters and pitch optimisation when laying them onto the Kapton film. Multi-stacking of fibres within the host structure and variation in terms of several piezoelectric materials placed in the sandwich form - attached either with standard resin and / or other means, with metal shim or without metal shim.

The work on the PVDF piezoelectric materials could involve the study of the effect of material thickness to ascertain higher voltage output without compromising weight and flexibility. Also, the possibility of multi-layer structures should be considered, either with or without metal shim in between, as well as investigating variations of the dimensions and thickness of the sensing material.

\section{References}

[1] Energy - Consumption' A1 "Consumption by fuel, 1965 - 2008" (XLS). Statistical Review of World Energy 2009, BP. July 31, 2006.

http://www.bp.com/liveassets/bp_internet/globalbp/globalbp_uk_english/repo rts_and_publications/statistical_energy_review_2008/

[2] GOSS LEVI, B (2000). Nobel Prize in Chemistry Salutes the Discovery of Conducting Polymers, Physics Today, 53, 19

[3] VAN TURNHOUT, J. (1975). Thermally Stimulated Discharge of Polymer Electrets, Elsevier, Amsterdam

[4] KAWAI, H. (1969). The piezoelectricity of Polyvinylidene Fluoride, Jpn. J. Appl. Phys., 8, 975977 (1969).

[5] BAUER, S., NGERHARD-MULTHAUPT, R. \& SESSLER, G.M. (2004). Ferroelelectrts: Soft Electroactive Foams for Transducers, Physics Today, 57, 37-34

[6] EMFIT LTD., Vaajakoski, Finland, http://www.emfit.com/ 
[7] Sheneck, N.S., Paradiso, J.A. (2001). Energy Scavenging with Shoe-Mounted Piezoelectrics, IEEE Micro

[8] Starner, T. (1996). Human Powered Wearable Computing, IBM Systems J., vol. 35, nos. 3 and 4, 618-629

[9] Marsden, J.P. \& Montgomerey, S.R. (1971). Plantar Power for Arm Prosthesis Using Body Weight Transfer, Human Locomotor Engineering, Ins. Mechanical Engineers Press, London, 277-282

[10] Fletcher, R. (1996). Force Transduction Materials for Human technology Interface, IBM Systems J., vol. 35. 3 and 4, 630-638

[11] Antaki, J.F. et al. (1995). A Gait Powered Autologous Battery Charging System for Artificial Organs, Proc. 1995 American Society of Artificial Internal Organs Conf., Lippincott Williams \& Wilkins, Philadelphia, M588-M595

[12] Kymissis, J. et al. (1998). Parasitic Power Harvesting in Shoes, Second IEEE Int'l Conf. Wearable Computing, IEEE CS Press, Los Alamitos, Calif., 132-139

[13] Want, R. et al. (1992). The Active badge Location System, ACM Trans. Information Systems, vol 10, no. 1, 91-102

[14] Starner, T. (1996). Human-Powered Wearable Computing, IBM System Journal, vol. 35, no. $3 \& 4$, pp. 618-629

[15] Umeda, M., Nakamura, K. \& Ueha, S. (1996). Analysis of Transformation of Mechanical Impact Energy to Electrical Energy Using a Piezoelectric Vibrator, Japanese Journal of Applied Physics, Vol. 35, Part 1, No. 5B, May, pp. 3267-3273.

[16] Kymissis, J. et al. (1998). Parasitic Power Harvesting in Shoes, Second IEEE International Conference on Wearable Computing, pp. 132-139.

[17] Kawai, H. (1969). The Piezoelectricity of Poly9vinylidene Fluoride). Jpn. J. Appl. Phys. 8, 975-977

[18] Fukada, E. (2000). History and Recent Progress in Piezoelectric Polymers, IEEE Trans. Ultrason., Ferroelectr., Freq. Contr. 47, 1277-1290

[19] Newman, B. et al. (1992). A New Class of Ferroelectric Polymers, The Odd-numbered Nylons. Ferroelectrics 127, 229-234

[20] Miyata, S., et al. (1980). Piezoelectricity Revealed in the Copolymer of Vinylidene Cyanide and Vinyl Acetate. Polym. J. 12, 857-860

[21] Tasaka, S., et al. (1992). Ferroelectric Polarization Reversal in Polyureas With Odd Number of $\mathrm{CH}_{2}$ Groups. JPN. J. Appl. Phys. 31, L1086-L1088

[22] Tasaka, S., et al. (1994). Ferroelectric Behaviour in Aliphatic Polyurethanes. Jpn. J. Appl. Phys. 33, 1376-1379

[23] Tasaka, S., et al. (1995). Ferroelectric Behaviour in Aliphatic Polythioureas. Ferroelectrics, 203-210

[24] Sodano, H.A. (2003). Macro-Fibre Composites for Sensing, Actuating and Power Generation, Blacksburg, Virginia, 1-12

[25] Schwartz, M. (2002). Encylopedia of Smart Materials Vol. 1 and 2, pp. 780-792

[26] Ikeda, T. (1990). Fundemantals of Piezoelectricity, Oxford Sci. Oxford

[27] Mohammadi, F., et al. (2003). "Power Generation from Piezoelectric Lead Zirconate Titanate Fiber Composites", Symposium D," Electronics on Unconventonal Substrates-Electrotextiles and Giant-Area Flexible Circuits" as held at the 2002 MRS Fall Meeting, pp. D5.5.1

[28] Williams, R.B. (2002). "An Overview of Composite Actuators with Piezoceramic Fibers", Proceedings of 20th International Modal Analysis Conference, pp. 0704

[29] Xia, Z. et al. (1997). Ann. Rep., Conf. Electr. Insul. Diel. Phenom., IEEE, 471-474 
[30] Cao, Y., et al. (1998). IEEE Trans. Diel. Insul. 5, 58-62

[31] Xia, Z., et al. (1999). J. Physics. D:Appl. Phys. 32, L83-85

[32] Xia, Z., et al. (1999). Proc. 10 th Int. Symp. Electrets, IEEE, 23-26

[33] Xia, Z., et al. (2002). Influence of Porosity on Stability of Charge Storage and Piezoelectricity for Porous PTFE Film Electrets, these proceedings

[34] Schwodiauer, R., et al. (2002). IEEE Trans. Diel. Electr. Insul. 7, 578-586

[35] Schwodiauer, R., et al. (1999). Proc. 10th Int. Symp. Electrets, IEEE, 313-316

[36] Kunstler, W., et al. (2002). Appl. Phys. A, 70, 5-8

[37] Gerhard-Multhaupt, R., et al. (2000). IEEE Trans. Diel. Electr. Insul. 7, 480-488

[38] Wegener, M., et al. (2001). Proc. $4^{\text {th }}$ Int. Conf. Electr. Charges in Non-Conduct. Mater., Soc. Frans. Du Vide, Paris, 257-260

[39] Gerhard-Multhaupt, R., et al. (1999). Proc. 10 th Int. Symp. Electrets, IEEE, 273-276

[40] Kacprzyk, R. \& Motyl, E. (1994). Proc. $8^{\text {th }}$ Int. Symp. Electrets, IEEE, 703-708

[41] Kacprzyk, R., et al. (1995). J. Electrostatics, 35, 161-166

[42] Kacprzyk, R., aet al. (1997). J. Electrostatics, 39, 33-40

[43] Kawai, H. (1969). The Piezoelectricity of Poly(vinylidene Fluoride), Jpn. J. Appl. Phys. 8, 975977

[44] Fukada, E. (2000). History and Recent Progress in Piezoelectric Polymers, IEEE Trans. Ultrason. Ferroelectr. Freq. Contr. 47, 1277-1290

[45] Newman, B., et al. (1992). A New Class of Ferroelectric Polymers, The Odd Numbered Nylons, Ferroelectrics 127, 229-234

[46] Miyata, S., et al. (1980). Piezoelectricity Revealed in the Copolymer of Vinylidene Cyanide ans Vinyl Acetate, Polym. J. 12, 229-234

[47] Tasaka, S., et al. (1992). Ferroelectric Polarization Reversal in Polyureas With Odd Number of $\mathrm{CH}_{2}$ Groups. Jpn. J. Appl. Phys. 31, L1086-L1088

[48] Tasaka, S., et al. (1994). Ferroelectric Behaviour in Aliphatic Polyurethanes, Jpn. J. Appl. Phys. 33, 1376-1379

[49] Kacprzyk, R. (1995). Piezoelectric Properties of Nonuniform Electrets, J. Electrostatics 35, 161-166

[50] Gerhard-Multhaupt, R., et al. (1999). Priliminary Study of Multi Layer Space Charge Electrets With Piezoelectric Properties From porouse and Non Porouse Teflon Films, In: Proceedings, $10^{\text {th }}$ Int. Symp. On Electrets, IEEE Service Centre, Piscataway, NJ

[51] Kunstler, W., et al. (2000). Piezoelectricity of Porouse Polytetrafluoroethylene Single and Multiple Film Electrets Containing High Charge Densities of Both polarities, App. Phys. A $70,5-8$

[52] Kirjavainen, K. (1987). U. S. pat. 4,654,546

[53] Savolainen, A., et al. (1989). Sci. - Chem. A26, 583-59

[54] Gerhard-Multhaupt, R. (2002). Voided Polymer Electrets - New Materials, New Challenges, New Chances, 11th Int. Symp. On Electrets, 36-45

[55] Paajanen, M., et al. (2002). Sens. Actuat. 84, 95-102

[56] van Turnhout, J. (1999). in: Proc. 10 th Int. Symp. Electrets, IEEE, 785-788

[57] Crichton, G.C., et al. (1989). IEEE Trans. Electr. Insul. 24, 335-342

[58] McAllister, I.W. (1992). IEEE Trans. Electr. Insul. 27, 1202-1207

[59] McAllister, I.W. (1997). IEEE Trans. Electr. Insul. 4, 456-461

[60] Lindner, M. et al. (2002). J. Appl. Phys. 91, 5283-5287

[61] Lindner, M. et al. (2002). Dialectric Barrier Micro Discharges: Mechanism for the Charging of Piezoelectric Polymer Foams, these proceedings

[62] Baur, S. et al. (2002). Physics of Electromechanically Active Cellular Materials, these proceedings 
[63] Paajanen, M. et al. (2001). IEEE Trans. Diel. Electr. Insul. 8, 629-636

[64] Baurand, S. \& Baur-gogonea, S. (2003). Current practice in space charge and polarisation profile measurements using thermal techniques. IEEE Trans. Diel. Electr. Insul. 10, 883-902

[65] Bambery, K.R. \& Fleming, R.J. (1998). Space charge accumulation in two power cable grades of XLPE. IEEE Trans. Diel. Electr. Insul. 5, 103-109

[66] Baur, S. (1996). Poled polymers for sensors and photonic applications. J. Appl. Phys. 80, 55315558

[67] Wegener, M. et al. (2004). Electric poling and electromechanical charecterisation of $0.1 \mathrm{~mm}$ thick sensor films and $0.2 \mathrm{~mm}$ thick cable layers from piezoelectric poly(vinylidene fluoridetrifluoroethylene). IEEE Trans. Ultrason. Ferroelectric., Freq. Contr. 50, 921-931

[68] Mellinger, A. et al. (2004). Photostimulated discharge in electret polymers: an alternative approach for investigating deep traps. IEEE Trans. Diel. Electr. Insul. 11, 218-226

[69] Gentilman, R. Et al. (2003). Enhanced Performance Active Fiber Composites, Proceedings of SPIE's 10th Symposium on Smart Structures and Materials Conference, March 6

[70] Measurement Specialist Inc., 1000 Lucas Way, Hampton, VA 23666, Piezo Film Sensors Technical Manual, www.meas-spec.com

[71] Lindner, M. et al. (2004). Charged cellular polymers with "ferroelectretic" behavior, IEEE Transactions on Dielectrics and Electrical Insulation 2, 255-263

[72] Kirjavainen, K. (1987). lectromechanical film and procedure for manufacturing same, U.S. Patent No. 4,654,546

[73] Lindner, M. et al. (2002). Dielectric barrier microdischarges: mechanism for the charging of cellular piezoelectric polymers, Journal of Applied Physics 91, 5283-5287

[74] Neugschwandtner, G.S. et al. (2000). Large and broadband piezoelectricity in smart polymer-foam space-charge electrets, Applied Physics Letters 77, 3827-3829

[75] Amjadi, H. \& Sessler, G.M. (1995). Inorganic Electret Layers for Miniaturized Devices. In: Annual Report, Conference on Electrical Insulation and Dielectric Phenomena, pp. 668671, IEEE Service Centre, Piscataway

[76] Amjadi, H. (2000). Electret Membranes and Backelectrodes for Application in Micromechanical Transducers. J. Electrostatics 48, 179-191

[77] Kacprzyk, R. (1995). Piezoelectric Properties of Nonuniform Elecetrets, J. Electrostatics 35, 161-166

[78] Gerhard-Multhaupt, R. et al. (1999). Preliminary Study of Multi Layer Space Charge Electrets with Piezoelectric Properties from Porous and non Porous Teflon Films. In: Proceedings, $10^{\text {th }}$ Int. Symp. On Electrets, IEEE Service Centre, Piscataway, NJ

[79] Kunstler, K. et al. (2000). Piezoelectricity of Porous Polytetrafluoroethylene Single and Multiple Film Electrets Containing High Charge Densities of Both Polarities. App. Phys. A 70, 5-8

[80] Kirjavainen, K. (1987). Electromechanical Film and Procedure for Manufacturing Same. US Patent No. 4,654,546

[81] Treofan, Reunheim, Germany, http://www.treofan.com

[82] Wegner, M. et al. (2002). Corona-induced Partial Discharges, Internal Charge Seperation and Electromechanical Transducer Properties in Cellular Polymer Films. In: Proceedings, $11^{\text {th }}$ International Symposium on Electrets, 54-57, IEEE Service Centre, Piscataway

[83] Lindner, M. et al. (2002). Dielectric Barrier Microdischarges: Mechanism for the Charging of Cellular Piezoelectric Polymers. J. Appl. Phys. 91, 5283-5287

[84] Hillenbrand, J. \& Sessler, G.M. (2000). Piezoelectric Properties of a Polypropylene/air and Poly(vinylidene Fluoride)/air Composites. In: Annual Report, Conference on Electrical Insulation and Dielectric Phenomena, 161-165, IEEE Service Centre, Piscataway 
[85] Bauer, S. et al. (2004). Ferroelectrets: Soft Electroactive Foams for Transducers. Physics Today $57,37-43$

[86] Bauer, S. et al. (2004). Do Ferroelectrets Always Behave Like Ferroelectrics?. In: Annual Report, Conference on Electrical Insulation and Dielectric Phenomina, IEEE Service Centre, Piscataway

[87] Kressmann, R. (2001). Linear and Nonlinear Piezoelectric Response of Charged Cellular Polypropylene. J. Appl. Phys. 90, 3489-3496

[88] Paajanen, M. et al. (2001). Charging of Celluar Space Charge Electret Films in Various Gas Atmosphere. In: Annual Report, Conference on Electrical Insulation and Dielectric Phenomena, 24-27, IEEE Service Centre, Piscataway

[89] Wegener, M. et al. (2004). Two Step Inlation of Cellular Polypropylene Films: Void Thickness Increase and Enhanced Electromechanical Properties. J. Phys. D: Appl. Phys. 37, 623-627

[90] Zhang, X. Et al. (2004). Piezoelectric $d_{33}$ Coefficient of Cellular Polypropylene Subjected to Expansion by Pressure Treatment. Appl. Phys. Lett. 85, 1226-1228

[91] _, Improvement of Piezoelectric Activity of Cellular Polymers Using a Double Expansion Process, J. Phys. D: Appl. Phys. 37, 2146-2150 (2004).

[92] Neugschwandtner, G.S. et al. (2001). Piezo and Pyroelectricity of a Smart Polymer-foam Space-charge Electret. J. Appl. Phys. 89, 4503-4511

[93] Suutala, J. \& Roning, J. (2004). Towards the Adaptive Identification of Walkers: Automated Feature Selection of Footsteps Using Distinction-sensitive lvq. In: Int'l. Workshop on Processing Sensory Information for Proactive Systems (PSIPS 2004), Oulu, Finland, June 14-15

[94] Lekkala, J. et al. (1996). EMF-force Sensor- a Flexibile and Sensitive Electret Film for Physiological Applications. Medical \& Biological Engineering \& Computing 34, Supplement 1, Part 1

[95] Nykanen, H. et al. (1999). Active Control of Sound Based on Utilizing EMFi-technology. In:Proceedings, ACTIVE 99, 1159-1170, Ft. Lauderdale, Dec. 4-6

[96] _, Piezoelectric materials in devices (Ed.: N. Setter), EPFL Swiss Federal Institute of Technology, Lausanne (2002).

[97] Bauer, S. et al. (2004). Phys. Today, 57, 37-43

[98] Paajanen, M. et al. (2001). IEEE Trans. Dielectr. Electr. Insul., 8, 629 -636

[99] Information of the company Emfit Ltd., Finland, http:/ / www.emfit.com.

[100] Lekkala, J \& Paajanen, M. (1999). In: Proceedings of the 10th International symposium on Electrets (Eds.: A. A. Konsta, A. Vassilikou-Dova, K. Vartzeli-Nikaki), IEEE, Piscataway, NJ, 743- 746

[101] Siivola, J. et al. (1993). Med. Biol. Eng. Comput., 31, 634- 635

[102] Information of the company Screentec, Finland, http:/ / www.screentec.com.

[103] Lekkala, J. (1997). Ind. Horizons, Dec., 12- 13

[104] Information of the company B-Band, Finland, http:/ / www.b-band.com.

[105] Hillenbrand, J. \& Sessler, G.M. (2004). J. Acoust. Soc. Am., 3267- 3270

[106] Paajanen, M. et al. (2002). In: Proceedings of the 11th International Symposium on Electrets (Ed.: R. Fleming), IEEE, Piscataway, NJ, 191 -194

[107] Kressmann, R. \& Schallwandler, K. (2002). Mit. Interner Polarisation auf Polymerbasis sowie Siliziummikromechanik, Shaker, Aachen, (in German)

[108] Advanced Cerametrics Incorporated, P.O. Box 128, 245 North main Street, Lambertville, New Jersey 085300128.

[109] Measurement Specialists Incorporated, 100 Lucas way, Hampton, VA 23666. 


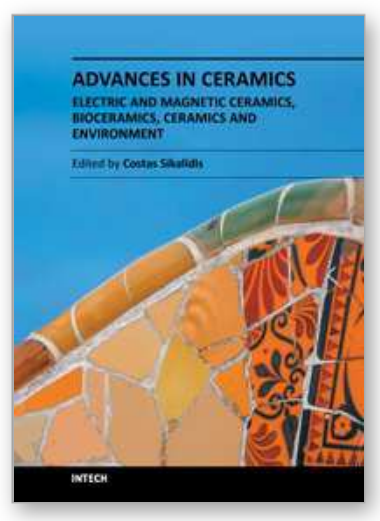

\author{
Advances in Ceramics - Electric and Magnetic Ceramics, \\ Bioceramics, Ceramics and Environment \\ Edited by Prof. Costas Sikalidis
}

ISBN 978-953-307-350-7

Hard cover, 550 pages

Publisher InTech

Published online 06, September, 2011

Published in print edition September, 2011

The current book consists of twenty-four chapters divided into three sections. Section I includes fourteen chapters in electric and magnetic ceramics which deal with modern specific research on dielectrics and their applications, on nanodielectrics, on piezoceramics, on glass ceramics with para-, anti- or ferro-electric active phases, of varistors ceramics and magnetic ceramics. Section II includes seven chapters in bioceramics which include review information and research results/data on biocompatibility, on medical applications of alumina, zirconia, silicon nitride, $\mathrm{ZrO} 2$, bioglass, apatite-wollastonite glass ceramic and b-tri-calcium phosphate. Section III includes three chapters in applications of ceramics in environmental improvement and protection, in water cleaning, in metal bearing wastes stabilization and in utilization of wastes from ceramic industry in concrete and concrete products.

\title{
How to reference
}

In order to correctly reference this scholarly work, feel free to copy and paste the following:

Imran Patel (2011). Ceramic Based Intelligent Piezoelectric Energy Harvesting Device, Advances in Ceramics Electric and Magnetic Ceramics, Bioceramics, Ceramics and Environment, Prof. Costas Sikalidis (Ed.), ISBN: 978-953-307-350-7, InTech, Available from: http://www.intechopen.com/books/advances-in-ceramics-electricand-magnetic-ceramics-bioceramics-ceramics-and-environment/ceramic-based-intelligent-piezoelectricenergy-harvesting-device

\section{INTECH}

open science | open minds

\author{
InTech Europe \\ University Campus STeP Ri \\ Slavka Krautzeka 83/A \\ 51000 Rijeka, Croatia \\ Phone: +385 (51) 770447 \\ Fax: +385 (51) 686166 \\ www.intechopen.com
}

\author{
InTech China \\ Unit 405, Office Block, Hotel Equatorial Shanghai \\ No.65, Yan An Road (West), Shanghai, 200040, China \\ 中国上海市延安西路65号上海国际贵都大饭店办公楼 405 单元 \\ Phone: +86-21-62489820 \\ Fax: $+86-21-62489821$
}


(C) 2011 The Author(s). Licensee IntechOpen. This chapter is distributed under the terms of the Creative Commons Attribution-NonCommercialShareAlike-3.0 License, which permits use, distribution and reproduction for non-commercial purposes, provided the original is properly cited and derivative works building on this content are distributed under the same license. 